\title{
Evaluation of acute intraperitoneal toxicity of new germanium coordination compounds
}

\author{
Ihor Kryvoi*, Iryna Nizhenkovska, Violetta Narokha, Olena Kuznetsova \\ Bogomolets National Medical University, Department of Pharmaceutical, Biological and Toxicological \\ Chemistry, Pushkinska str. 22, 01004 Kyiv, Ukraine
}

\section{Introduction}

Complex compounds of metals with bioorganic ligands is one of the promising areas for the search for new active substances with a high safety profile, which can subsequently form the basis of new medicines. Such substances include complex compounds of germanium with organic acids, which already have shown antioxidative, membrane-, neuro-, hepato- and cardioprotective effect in a range of studies (Kresyun et al., 2004; Narokha et al., 2016).

To study the safety and evaluate the toxicity of new compounds, an important step is the determination of acute toxicity in rodents, which makes it possible to estimate the feasibility of further studies of the compounds, adequately select doses for possible subsequent studies and draw conclusions about possible damage to organs and systems.

\begin{abstract}
Aim
The goal of this study was to determine the acute intraperitoneal toxicity of three new germanium coordination compounds (OE-3, OE-6, OE-7) by estimation of its median lethal doses $\left(\mathrm{LD}_{50}\right)$ on mice, identify its toxic effects and classify due to toxicity class.
\end{abstract}

\section{Materials and methods}

Germanium coordination compounds with oxyethyliden diphosphonic acid and nicotinamide (OE-3, OE-6, OE-7) were synthesized in laboratory of Department of General Chemistry and Polymers of Odessa I.I.Mechnikov National University under the supervision of professor Seifullina I.I.

The study was conducted in adult (8-12 weeks) CD-1 mice, weighing 18-22g. The animals were maintained (including euthanasia) pursuant to the European Convention for the Protection of Vertebrate Animals used for Experimental and Other Scientific Purposes (2016/63/EU). The animals were fed balanced diet and had free access to water in the animal house (vivarium) of the Bogomolets National Medical University (Kyiv, Ukraine). Animals were kept in their cages for one week before the beginning of the experiment for acclimatization to the laboratory conditions. Individual weights of mice were determined before germanium compound administration and weekly thereafter. Each dose of each substance was administered intraperitoneal as a single dose to groups of seven mice. A dose range was selected as five dose levels with an upper limit of $1000,0 \mathrm{mg} / \mathrm{kg}$ of body weight for each substance $(62,5 ; 125,0 ; 250,0 ; 500,0$ and $1000,0 \mathrm{mg} / \mathrm{kg})$ which corresponds to the maximum dose for the IV toxicity class which is limiting for an acute toxicity study (Stefanov, 2001). After injection of germanium

\footnotetext{
*igor.kryvoy@gmail.com
} 
complexes, mice were observed with special attention during the first $4 \mathrm{~h}$ and daily thereafter, for a total of 14 days generally. Signs of toxicity and mortality were recorded.

The LD50 values based on mortality data, were calculated according to the probit analysis method and method of Litchfield and Wilcoxon at the 95\% confidence level.

\section{Results and discussion}

Obtained results of mortality rate and toxicity after substances administration shows that death of mice injected with OE-7 occurred starting from the dose of $125 \mathrm{mg} / \mathrm{kg}$ while death of mice injected with OE-3 or OE-6 occurred starting from the dose 250 $\mathrm{mg} / \mathrm{kg}$. $\mathrm{LD}_{50}$ values of OE-3, OE-6, OE-7 were ranged between 300 and $400 \mathrm{mg} / \mathrm{kg}$ of body weight, which corresponded IV class of toxicity - slightly hazardous substances and also corresponded the literary data on the toxicity of germanium compounds (Godovan, 2008; Narokha, 2018). According to the degree of toxicity substances are located as follows: OE-7>OE-6>OE-3.

With the substances administration, rapid developments of toxic effects were observed. In mice, there was a reduced activity, lethargy and, in case of mortality, dyspnea, tachycardia and tonic seizures: a constant muscle contraction accompanied by persistent extension of the hind limbs. Moreover, the symptoms of OE-7 were more pronounced, which is probably due to the greater toxicity of this substance.
Death predominantly occurred within an hour after the introduction of substances and if the rodent survived, after 24 hours it felt cheerful. Such effects indicate the toxic effects of high concentrations of germanium complexes on the central nervous system and neuromuscular innervation.

There were no significant changes in weight in animals recorded.

\section{Conclusions}

Three new germanium coordination compounds with bioligands (OE-3, OE-6 and OE-7) referring to IV toxicity class - slightly hazardous substances, $\mathrm{LD}_{50}$ of these compounds lies in the range 300-400 $\mathrm{mg} / \mathrm{kg}$ of body weight, which confirms their safety and the feasibility of further animal studies using these compounds.

\section{References}

Godovan, V.V., 2008. Pharmacological properties of new derivatives of germanium salts of diphosphonic acids with bioligands, Odessa, 32p.

Kresyun, V., Shemonayeva, K., Vidavska, A.G., 2004. Pharmacological characterization of compounds of germanium. Clin. Pharm. 4, 64-68.

Narokha, V.P., 2018 Experimental study of the pharmacodynamics of germanium coordination compounds in anthracyclin intoxication, Kyiv, 219p.

Narokha, V.P., Nizhenkovska, I.V., Kuznetsova, O.V., Afanasenko, O.V., 2016. Analysis of coordination compound of germanium with nicotinic acid as potential cardioprotector. Mac. Pharm. Bull. 62, 8384.

Stefanov, O.V., 2001. Preclinical studies of drugs, Kyiv, $527 \mathrm{p}$. 